\title{
Intramural esophagic hematoma secondary to coumarinic anticoagulation: a case report
}

\author{
Álvaro M Quintero*1, María E Gaviria² ${ }^{2}$ Jon K Balparda ${ }^{2}$ and \\ Héctor R Cuervo ${ }^{3}$
}

\begin{abstract}
Address: ${ }^{1}$ Department of cardiology, Clínica Cardiovascular, Medellín, Colombia, ${ }^{2}$ School of medicine, SIFAM Research Group, Universidad Pontificia Bolivariana, Medellín, Colombia and ${ }^{3}$ Department of general medicine, Clínica Cardiovascular, Medellín, Colombia

Email: Álvaro M Quintero* - alvaroquintero@une.net.co; María E Gaviria - eliza2631@ hotmail.com; Jon K Balparda - jonbalparda@une.net.co; Héctor R Cuervo - hrodrigo@une.net.co

* Corresponding author
\end{abstract}

Published: 2I December 2009

Cases Journal 2009, 2:9368 doi:10.1186/1757-1626-2-9368

This article is available from: http://www.casesjournal.com/content/2/I/9368

(C) 2009 Quintero et al; licensee BioMed Central Ltd.

This is an Open Access article distributed under the terms of the Creative Commons Attribution License (http://creativecommons.org/licenses/by/2.0), which permits unrestricted use, distribution, and reproduction in any medium, provided the original work is properly cited.
Received: 20 October 2009

Accepted: 21 December 2009

\begin{abstract}
Esophagic Intramural Hematoma is an uncommon clinical condition, with a prognosis which is essentially benign. On most cases, a predisposing or precipitating factor may be seen, with the most common ones being the history of esophagic instrumentation, food impactations and thrombocytopenia. In the following manuscript, the authors present the case of a 54-years-old male with history of valve replacement surgery, who was treated at the Clinica Cardiovascular (Medellin, Colombia), with a clinical case of Intramural Esophagic Hematoma that was later confirmed to be due to a Coumarinic overanticoagulation. On this case, it is evidenced that Intramural Esophagic Hematoma is an unrecognized complication of Courmarinic anticoagulation therapy.
\end{abstract}

\section{Introduction}

IEH was described for the first time by Williams in 1957[1]. It is an very uncommon clinical entity[2], but fortunately its prognosis remains essentially benign with only very few patients requiring an invasive therapeutic approach[3]. Nevertheless, a high level of suspicion is required in order to make an accurate diagnosis due to the unspecific nature of its clinical presentation.

In the present article, we describe the case of a 54 year old male individual who had undergone aortic mechanical valve replacement surgery in our institution, and as a result needed lifetime anticoagulation therapy with warfarin. He presented to us approximately two and a half months after the procedure with symptoms of dysphagia and was eventually diagnosed with a symptomatic IEH secondary to supratherapeutic anticoagulation despite usual doses of warfarin and strict adherence to recommendations.

\section{Case presentation}

A 54 year old male underwent coronary artery bypass graft (CABG) surgery and replacement of his native aortic valve for a mechanical prosthesis for treatment for severe aortic insufficiency at our institution. His postoperative course was uneventful and after initiation of warfarin therapy and careful monitoring of his Intrenational Normatized Ratio (INR) to ensure therapeutic anticoagulation (target INR 2.5-3.5), the patient was discharged home to continue ambulatory warfarin therapy at a dose of $5 \mathrm{mg}$ daily.

48 days after surgery, the patient was readmitted to our institution because of severe pain in his left flank. During this hospitalization he was diagnosed with a large splenic 
hematoma and an associated massive hemoperitoneum, his INR at admission was 9.4. He was initially managed conservatively, but after two days it was decided that the patient required invasive treatment with splenectomy and drainage of the hemoperitoneum because of a drop of 4 $\mathrm{gr} / \mathrm{dl}$ in hemoblobin value within a day. At discharge the warafrin dose was readjusted to $2.5 \mathrm{mg}$ with an INR of 2.8.

His second postoperative course was uncomplicated until 25 days later (73 days after the initial valve replacement surgery), when he presented to our Emergency Department with a 24 hour history of frank dysphagia and associated dyspepsia and flatulence.

Upon initial evaluation he was noted to be hemodynamically stable with a blood pressure of $122 / 76 \mathrm{mmHg}$ and a heart rate of 65 beats per minute and he was on beta blocker therapy. Upon further evaluation, a mildly bleed- ing, vesicular lesion has found on his right oropharynx; there was not tenderness to neck palpation or regional lymphadenopathy. The patient denied a history of obvious spontaneous bleeding or painful swallowing. Laboratory tests ordered at that time revealed supratherapeutic anticoagulation with an INR "infinite", and a hemoglobin and hematocrit levels of $10.1 \mathrm{gr} / \mathrm{dL}$ and $31,4 \%$ respectively (Table 1. Other laboratory tests included the following: Leukocytes 11.610, Neutrophil 76\%, serum creatinine $0,9 \mathrm{mg} / \mathrm{dL}$, blood ureic nitrogen (BUN) $14 \mathrm{mg} /$ $\mathrm{dL}$. Warfarin therapy was immediately discontinued in an attempt to normalize his clotting parameters.

The initial differential diagnosis included acute pharyngitis and azitromycin was prescribed. However, due to a persistent complaint of dysphagia, a diagnostic upper endoscopy (EGD) was performed. The EGD revealed a pale distal mucosa and the presence of a large submucosal

Table I: Relevant INR values during hospitalization.

\begin{tabular}{|c|c|c|}
\hline Day of Hosp. & INR & Comments \\
\hline 1 & "Infinite" & Initial INR; longer than I20. Warfarin was suspended. \\
\hline 2 & "Infinite" & Longer than I20. Patient develops hematuria. SDE diagnoses IEH. \\
\hline 3 & "Infinite" & Longer than 120.4 units of FFP are given. \\
\hline 4 & 6.2 & 3 units of FFP are given. \\
\hline 5 & 5.6 & 4 units of FFP are given. \\
\hline 6 & 7.0 & - \\
\hline 7 & 7.7 & First dose of Vitamin $\mathrm{K} 10 \mathrm{mg}$ is administered. \\
\hline 8 & 1.5 & Hematuria resolves. \\
\hline 10 & 2.4 & - \\
\hline 12 & 3.6 & Second dose of Vitamin K $10 \mathrm{mg}$ is administered. \\
\hline 16 & 1.9 & - \\
\hline 19 & 2.2 & - \\
\hline 21 & 1.8 & - \\
\hline 23 & 1.5 & Warfarin $2.5 \mathrm{mg}$ oral is started again. \\
\hline 26 & 2.0 & Normal SDE. \\
\hline 29 & 2.7 & - \\
\hline 31 & 2.5 & Patient is discharged. \\
\hline
\end{tabular}

INR = International Normalized Ratio. SDE = Superior Digestive Endoscopy. IEH = Intramural Esophagic Hematoma. FFP = Fresh Frozen Plasma. 

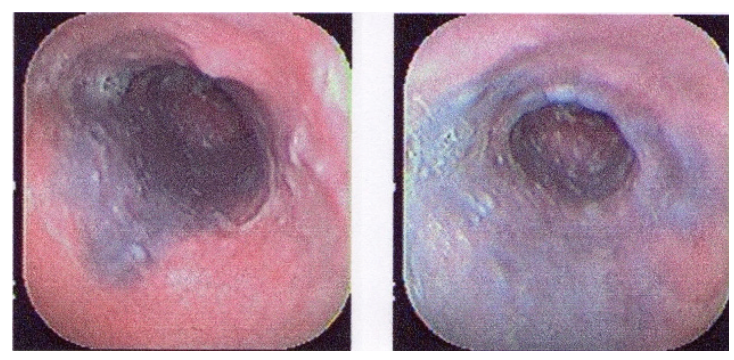

Figure I

Superior Digestive Endoscopy showing the presence of great submucosal ecchymosis compatible with Intramural Esophagic Hematoma. Courtesy of William Darío Lopera Lotero, MD.

ecchymosis/hematoma that extended to the level of the cardias. These findings were consistent with an IEH (Figure 1).

During the course of his hospitalization, in addition to his diagnosis of IEH, our patient had other clinical and laboratory manifestations that reflected his supratherapeutic anticoagulation status, including macroscopic hematuria and severe worsening anemia. He received multiple transfusions of fresh frozen plasma (FFP) and packed red blood cells (PRBC), as well as administration of vitamin K. His coagulation parameters eventually returned to normal and after an observation period of ten days, anticoagulation with warfarin was restarted with careful serial monitoring of his INR, remaining within therapeutic level throughout the rest of his hospital stay and without any bleeding complications.

Five days before discharge from the hospital, an EGD was performed, which showed no evidence of the findings of the previous EGD, performed 24 days earlier, suggesting a spontaneous resolution of the IEH (Figure 2). After discharge, the patient had a close clinical follow up, and his INR was monitored at frequent intervals. His symptoms improved completely and he has had no further clinical or laboratory evidence of coumarinic toxicity.

\section{Discussion}

IEH is an uncommon, although well documented cause of acute thoracic pain[4], often associated with additional digestive symptoms such as dysphagia and hematemesis $[5,6]$. The condition has been described to occur spontaneously as consequence of an abrupt rise on intraesophageal pressure [7,8], although in most cases, a precipitating event may be found, the most common being a history of previous esophageal instrumentation[5].

According to Martínez et al[5], the most common clinical manifestation among patients with IEH is acute thoracic

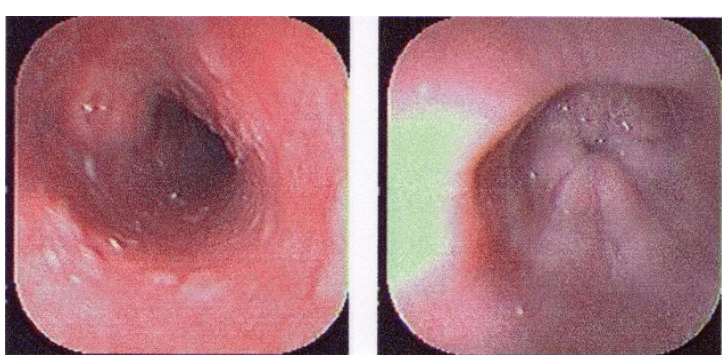

Figure 2

Superior Digestive Endoscopy showing the absence of submucosal ecchymosis, compatible with spontaneous resolution of Esophagic Hematoma. Courtesy of William Darío Lopera Lotero, MD.

pain in $87 \%$ of cases, followed by hematemesis, dysphagia and pain while swallowing in 70\%, 26\% and 26\% of cases respectively. It is important to mention that in up to $60 \%$ of cases there is a history of a predisposing factor, most commonly a history of esophageal instrumentation, food impaction and bleeding dyscrasias like thrombocytopenia $[5,9,10]$. Well documented cases of IEH secondary to anticoagulation therapy with warfarin are sparse in worldwide literature, which makes the present report all the more relevant $[7,11,12]$.

The case we have just presented is, to the author's knowledge, the first reported case of IEH secondary to coumarinic anticoagulation reported from a Latin American institution and one of the few reported from around the world $[7,11,12]$. Coumarinics, in particular warfarin, are medicines prescribed frequently for a myriad of medical conditions and in all sorts of patients. The practicing physician should be aware of the potential complications of anticoagulation, including IEH, a condition that albeit uncommon, may carry a lethality of up to $7-9 \%$ in patients with other associated commorbidities[7].

In this case, it is fairly clear that this rare complication was the result of a supratherapeutic level of anticoagulation with warfarin, medication which was clinically indicated after the patient's CABG and valve replacement surgery. Upon presentation to our emergency department, this individual had an INR reported as $>120$ seconds, otherwise known as an "infinite INR", reflecting the laboratory's inability to accurately calculate it. Although there was no history of immediate active bleeding prior to presentation, our patient had recently been hospitalized with a splenic hematoma and hemoperitoneum that required surgical intervention and drainage, and at this time his INR level was found to be elevated above the therapeutic range. This severe clotting dysfunction may be enough to justify spontaneous bleeding on multiple sites of the human body, including those that may not be evident to a careful physical examination. 
This clinical case also highlights the benign course of IEH $[3,4,13]$, as the condition resolved spontaneously once clotting mechanisms are normalized. It must be stressed however that its benign course is dependent on the consideration of this entity in the differential diagnosis and work up of a patient who presents with symptoms and signs compatible with IEH and who has a predisposing condition making him prone to developing it, hence stressing the importance of this report.

\section{Consent}

Written informed consent was obtained from the patient for publication of this case report and accompanying images. A copy of the written consent is available for review by the Editor-in-Chief of this journal.

\section{Competing interests}

The authors declare that they have no competing interests.

\section{Authors' contributions}

AMQ and HRC were involved in the medical treatment of the patient, MEG and JKB reviewed the patient's medical chart and wrote the initial draft for the article. All authors were involved in writing and reviewing the article. All authors have read and approved the final version of the manuscript.

\section{Acknowledgements}

The authors wish to thank William Darío Lopera Lotero, MD, for collaborating with the endoscopy pictures for this article. The author also acknowledge all the help provided by the Clínica Cardiovascular and the Universidad Pontificia Bolivariana teams regarding development and publication of this article. Great and valuable help was obtained from Carlos Jaramillo Hoyos, MD, Associate Infectious Disease Department, Geisinger Medical Center (Danville, PA).

\section{References}

I. Williams B: Case report; oesophageal laceration following remote trauma. Br J Radiol 1957, 30:666-8.

2. Hess U, Brücher BL, Cavallaro A, Hanning C, Stein HJ, Ott R: Intramural esophageal hematoma after cardioversion. Dis Esophagus 1997, 10:225-8.

3. Shay SS, Berendson RA, Johnson LF: Esophageal hematoma. Four new cases, a review, and proposed etiology. Dig Dis Sci I98I, 26:1019-24.

4. Lu MS, Liu YH, Liu HP, Wu YC, Chu Y, Chu Jl: Spontaneous intramural esophageal hematoma. Ann Thorac Surg 2004, 78:343-5.

5. Martínez JD, Rey MH, Marulanda JC, Garzón MA, Molano JC: Hematoma intramural esofágico. Rev Col Gastroenterol 2005, 20:76-9.

6. Lauzon SC, Heitmiller RF: Transient esophageal obstruction in a young man: an intramural esophageal hematoma? Dis Esophagus 2005, 18:127-9.

7. Iñarrairaegui M, Jiménez FJ, Zozaya JM, Vila Jl, Arín A, Cástan B: Hematoma esofágico gigante: posible relación con dosis pequeñas de aspirina. Gastroenterol Hepatol 2004, 27:460-3.

8. Thomasset SC, Berry DP: Spontaneous intramural esophageal hematoma. J Gastrointest Surg 2005, 9:155-6.

9. Younes Z, Johnson DA: The spectrum of spontaneous and iatrogenic esophageal injury: perforations, Mallory-Weiss tears, and hematomas. J Clin Gastroenterol 1999, 29:306-17.

10. Ashman FC, Hill MC, Saba GP, Diaconis JN: Esophageal hematoma associated with thrombocytopenia. Gastrointest Radiol 1978, 3: I15-8.
II. Yamashita K, Okuda H, Fukushima H, Arimura Y, Endo T, Imai K: A case of intramural esophageal hematoma: complication of anticoagulation with heparin. Gastrointest Endosc 2000, 52:559-61.

12. Vyas H, Desal D, Abraham P, Joshi A: Heparin theraphy for mistaken cardiac diagnosis in Boerhaave's syndrome. Indian J Gastroenterol 2004, 23:72-3.

13. Geller A, Gostout C]: Esophagogastric hematoma mimicking a malignant neoplasm: clinical manifestations, diagnosis, and treatment. Mayo Clin Proc 1998, 73:342-5.
Publish with Bio Med Central and every scientist can read your work free of charge

"BioMed Central will be the most significant development for disseminating the results of biomedical research in our lifetime. "

Sir Paul Nurse, Cancer Research UK

Your research papers will be:

- available free of charge to the entire biomedical community

- peer reviewed and published immediately upon acceptance

- cited in PubMed and archived on PubMed Central

- yours - you keep the copyright

Submit your manuscript here:

http://www.biomedcentral.com/info/publishing_adv.asp
BioMedcentral 